\title{
Sıkıştırma ile Ateşlemeli Motorlarda Bilgisayar Destekli Enerji ve Ekserji Analizi
}

\author{
Computer Aided Energy and Exergy Analysis in Compression Ignition Engines \\ İker Turgut YILMAZ ${ }^{1}$ \\ ${ }^{1}$ Marmara Üniversitesi Teknoloji Fakültesi Makine Mühendisliği Bölümü, 34722, İstanbul, Türkiye
}

$\ddot{O} \mathbf{z}$

Kaynakları daha verimli kullanmanın en iyi yolu, enerji ve ekserji arasındaki ilişkiyi anlamaktır. Termodinamiğin birinci kanunu enerji analizi ile ilişkilidir. Bu kanun enerjinin niceliği ile alakalıdır. Enerji analizi sistemin enerji ve entalpi transferlerini açıklamaya yardımcı olur. Enerji yok edilemezken ekserji yok edilebilir. Ekserji bir sistemden elde edilebilecek maksimum teorik iş olarak tanımlanır. Diğer taraftan ekserji analizi termodinamiğin ikinci yasasına dayanır. Termodinamiğin ikinci kanunu enerjinin niteliği ile alakalıdır. Bir sistemin kullanılabilirliği ekserji analizi ile belirlenebilir. Bir sistemin termodinamik detaylarının belirlenmesi istenildiğinde hem enerji, hem de ekserji analizi yapılmalıdır.

Ekserji ve enerji analizleri çeşitli alanlara uygulanabilir. Ekserji analizi, içten yanmalı motorlar konusunda önemli bir rol oynamaktadır. $\mathrm{Bu}$ çalışmada enerji ve ekserji analizi yapabilen bir programın tanıtımı ve yapısı gösterilmiş̧ir. Program sayesinde hızlı ve güvenilir sonuçlar elde edilebilecektir.

Anahtar Kelimeler: Enerji analizi, Ekserji analizi, İçten yanmalı motor, Bilgisayar destekli analiz

\begin{abstract}
The best way of using the resources more efficiently is understanding the relationship between energy and exergy. The first law of thermodynamics associates with the energy analysis. This law of thermodynamics is about quantity of energy. Energy analysis helps explaining the energy and enthalpy transfers of the system. Energy cannot be destroyed but exergy can be destroyed. Exergy is defined as the maximum theoretical work obtained from a system. On the other hand, the exergy analysis is based on the second law of thermodynamic. The second law of thermodynamics is about quality of energy. The availability of the system can be described by the exergy analysis. If the thermodynamic details of a system want to be known, both energy and exergy analysis have to be applied to system.

Energy and exergy analyses are applied in different fields. Exergy analysis has an important role in internal combustion engines. In this study, introduction and structure of an energy and exergy analysis program will be showed. This program will provide fast and reliable results.
\end{abstract}

Keywords: Energy analysis, Exergy analysis, Internal combustion engine, Computer aided analysis

\section{GİRiş}

Ekserji, bir sistemin referans çevreyle denge haline gelene dek o sistemden alınabilecek maksimum teorik iş olarak tanımlanabilir. Enerji, ekserji ve entropi analizleri tüm bilimsel ve mühendislik alanlara uygulanabilir. Entropi üretimi, sürecin ve performansın optimize edilmesi için aşılması gereken engellerden bir tanesidir [1].

Bir enerji kaynağının ekserjisi, kaynağın ve çevrenin birbirleriyle olan potansiyel etkileşimlerinin sonucudur. Bu nedenle ekserji, enerji kaynağının hal değişimleri ve çevrenin sıcaklık, basınç, kimyasal bileşim gibi hal parametrelerinin bir fonksiyonudur [2]. 
İçten yanmalı motorda ekserji uygulamaları önemli bir yere sahiptir. İçten yanmalı motorlar kara ve deniz araçlarında kullanıldığ gibi sabit güç istasyonlarında da kullanılmaktadırlar. Farklı sistemlerde kullanılan içten yanmalı motorlara ekserji analizi uygulanabilir [1].

Bir içten yanmalı motorun birinci ve ikinci kanun verimliliklerini iyileştirebilmek için enerji ve ekserji yıkımı azaltılmalıdır. Bu nedenle, enerji ve ekserji analizinin temel amacı olan enerji ve ekserji yıkımlarını belirlemek önemli$\operatorname{dir}[3]$.

Motor performansının ve çeşitli süreçlere bağlı verimsizliklerin nicelik bakımından değerlendirilmesi söz konusu olduğunda, en iyi seçim ikinci kanun analizidir. İkinci kanun analizi ekserji ile ilgilidir. Ekserji, sistemin faydalı iş üretme potansiyeli olarak açılanabilir. Enerjinin aksine ekserji yok edilebilir. Ekserji yıkımı, içten yanmalı bir motorda faydalı mekanik iş üretmek için yakıt ekserjisinin yetersiz kullanımından kaynaklanmaktadır. Ekserji yıkımının azaltılabilmesi için yakıtın daha verimli kullanılarak motor performansının iyileştirilmesi gereklidir [4].

Silindir içerisindeki dolgu kütlesine etkisinden ötürü volümetrik verim, motor performansı açısından önemli bir parametredir. Dolgu kütlesi, doğrudan motorun tork ve güç üretimini etkiler. Ayrıca yakıt özellikleri de volümetrik verimi etkileyebilir. Örneğin benzinin yüksek buharlaşma gizli 1sısı, yakıtın buharlaşması esnasında emme dolgusunu soğutucu bir etki gösterir. Bu nedenle hava/yakıt karışımının yoğunluğu ve volümetrik verimi artar [3]. İçten yanmalı motorlarda kullanılan yakıtlar farklılaştıkça, performans ve verimdeki değişiklikleri belirlemek için termodinamiğin ikinci kanununa bağlı olarak bir termodinamik analiz yapılmasına ihtiyaç duyulur [5].

Silindir içindeki yanma ve isı transferi olaylarının temel parametreleri, kayıpların ve ekserji yıkımının dâhil edildiği termodinamiğin ikinci kanunu ile belirlenebilir. Bu yaklaşımda, yakıtın temel bileşenlerine dayanılarak, yakıtın ekserjisi belirlenir. İçten yanmalı motorlar çeşitli yakıt ve yakıt karışımları ile çalıştırılabilirler. Bununla birlikte, aynı alt ısıl değere fakat farklı özelliklere sahip yakıtların kimyasal ekserjileri farklılık gösterebilir. Yakıtın viskozite ve yoğunluk gibi özellikleri, silindir içindeki hava/yakıt karışımını değiştirebilir. Bu durumunda yanma verimi de değișecektir. Motorlarda kullanılan farklı yakıtlar uluslararası kalite standartlarını yakalamak zorundadır. Bu nedenle motora gönderilen yakıtın ekserjik değerlendirilmesi yapılmalıdır. Ekserji analizi, yakıtın kullanılabilirliğinin değerlendirilmesinde kullanılan etkili bir yöntemdir [6].

Bir içten yanmalı motorda, yakıt ve havanın bir yanma odasına girdiği ve yanma sonucu oluşan ürünlerin egzoz gazı olarak atmosfere atıldığı kabul edilir. Soğutma suyu sisteme girer ve çıkar. Yağlama yağı ise kontrol hacminin çevresindedir. Isı değişiminin motor ve çevre arasında olduğu varsayılmaktadır [7].

İçten yanmalı bir motorda, yanma işlemi ile yakıtın kimyasal enerjisi 1sı enerjisine çevrilir. Termodinamiğin birinci kanununa göre enerjinin bir kısmı işe dönüştürülürken, bir kısmı egzoz gazı ve soğutma suyu ile çevreye bırakılır. Geri kalan kısmı ise motorda meydana gelen 1sı yayınımı ve sürtünme kayıpları nedeni ile kaybolur. Termodinamiğin ikinci kanununa göre çevreye atılması gerekli atık ısı dışında, enerjinin geri kalanı içten yanmalı motorların verimliliğinin arttırılması için değerlendirilmelidir [8].

Özkan [1] dört silindirli, dört zamanlı direkt püskürtmeli bir dizel motorda farklı püskürtme basınçlarının enerji ve ekserji analizini gerçekleştirmiştir. Artan püskürtme basıncına bağlı olarak yanma verimi artarken, ısıl verim azalmıştır. Yanma sıcaklıklarının artması ile soğutma kayıpları yükselmiş ve ekserjik verim azalmıştır. Ekserji yıkımının ise püskürtme basıncından bağımsız olduğu görülmüsstür.

Doğal gaz-dizel çift yakıtlı $188 \mathrm{~kW}$ güç üretebilen bir motorda yapılan çalışmada ekserjik verim tek yakıtlı çalışmada \%14,6 ila \%35,4 arasında olurken, çift yakıtlı çalışmada $\% 9,57$ ile $\% 52,38$ arasında olmuştur. Tek yakıtlı çalışmada yıkılan ekserji 62 ile $206 \mathrm{~kW}$ arasında olurken egzoz gazı ekserjisi 8 ila $62 \mathrm{~kW}$ olmuştur. Çevreye atılan 1sı ise 1,7 ile $4,8 \mathrm{~kW}$ arasında olmuştur. Çift yakıtlı çalışmada ise yıkılan ekserji 10,4 ile 98,6 kW arasında olurken egzoz gazı ekserjisi 15,1 ila 36,4 kW olmuştur. Çevreye atılan 1sı ise 1,7 ile 2,9 kW arasında olmuştur [9].

Biyoetanol katkılı dizel ve biyodizel yakıtlarıyla çalıştırılan bir sıkıştırma ateşlemeli motorda, yakıtların enerjik ve ekserjik analizleri yapılmıştır. Çalışmanın sonucunda dizel yakıtın isıl ve ekserjik verimlerinin karışım yakıtlara göre yüksek çıktığı, verimlerin karışımlardaki biyodizel miktarına bağlı olarak azaldığı görülmüştür [10].

Tek silindirli, homojen dolgulu sıkıştırma ile ateşlemeli motorda yapılan çalışma sonucunda, emme havasının sıcaklığının arttırılması durumunda maksimum basıncın, faydalı işin ve entropi üretiminin düşeceği, silindir içi sıcaklıkların, 1S1 transferiyle meydana gelen ekserji kaybının ve toplam ekserjinin artacağı görülmüştür. Motor hızına bağlı olarak toplam ekserjinin artacağı, 1sı transferiyle meydana gelen ekserji kaybının ise azalacağı bildirilmiştir [11].

Dört silindirli dört zamanlı, su soğutmalı, direkt püskürtmeli, doğal emişli bir sıkıştırma ile ateşlemeli motorda, silindir içine hava jeti uygulanmasının sonuçlarının verildiği çalışmada, hava jeti uygulamasının yakıt ekserjisini, ısı transferiyle meydana gelen ekserji kaybını, egzoz gazının 
kimyasal ve termomekanik ekserjilerini arttırdığı görülmüştür. Hava jeti uygulamaması tersinmezliği arttırırken, ekserjik verimi düşürmüştür [12].

Jafarmadar ve Nemati yaptıkları çalışmada Fortran temelli bir yazılım ile dizel/biyodizel karışımlarıyla çalıştırılan homojen dolgulu sıkıştırma ile ateşlemeli bir motorda enerji ve ekserji analizleri yapmışlardır. Karışımdaki biyodizel oranının artmasına bağlı olarak ekserjik verim artarken ısı transferiyle meydana gelen ekserji kaybının azaldığı bildirilmiştir [13].

Gümüş ve Atmaca [14] doğalgaz-dizel çift yakıtlı sıkıştırma ile ateşlemeli bir motorda yaptıkları çalışmada, yakıt karışımlarının, motor yüklerinin ve hızlarının motorun enerjik ve ekserjik verimleri üzerine etkilerini incelemişlerdir. Çalışmaya göre, yüksek hızlarda çift yakıtlı çalışmalarda meydana gelen tersinmezlikler ile dizel yakıtlı çalışmada meydana gelen tersinmezlikler arasında önemli farklar oluşmadığı, düşük hızlarda ise çift yakıtlı çalışmalarda meydana gelen tersinmezliklerin dizel yakıtlı çalışmaya göre daha yüksek olduğu görülmüştür.

Dört silindirli, dört zamanlı, buji ile ateşlemeli bir motorda farklı yük ve devir şartlarında kullanılan farklı oktan sayılı $(91,93$ ve 95,3) yakıtların enerji ve ekserji analizi yapılmıştır. Çalışmada kullanılan deney motoru 91 oktan yakıtla çalışacak şeklide tasarlanmıştır. Çalışmaya göre 91 oktanlı yakıtın enerjik ve ekserjik verimleri diğer yakıtlara göre daha yüksek çıkmıştır [15].

Khaliq [16] organik Rankine çevrimi ile kombine edilmiş homojen dolgulu sıkıştırma ile ateşlemeli bir motoru hidrojen ve etanol ile çalıştırmıştır. Yazar, hidrojenin enerjik ve ekserjik verimlerinin etanolün enerjik ve ekserjik verimlerine göre daha yüksek olduklarını söylemiştir.

İçten yanmalı motora gönderilen yakıttan sağlanan 1sının bir kısmı faydalı mekanik işe çevrilirken büyük bir kısmı ise egzoz gazı, soğutma suyu ve diğer kayıplar ile çevreye atılır. Atık 1sının geri kazanılması hem motorun 1sıl verimini arttırır hem de yakıt tüketimini ve zararlı egzoz emisyonlarını azaltır. Bu nedenle farklı işletme koşullarında çalışan içten yanmalı motorlara uygulanacak enerji ve ekserji analizlerinin önemi açıktır [8].

Bu çalışmada biyodizel ve dizel yakıtlı dizel motorların ekserji analizine yardımcı olmak üzere Visual Basic programlama dili kullanılarak bir bilgisayar programı geliştirilmiştir. Bu bilgisayar programı geliştirilirken matematiksel hesaplamalardan kaynaklanan hataların giderilmesi ve zaman tasarrufu göz önüne alınmıştır.

\section{ANALIZ YÖNTEMLERİ VE PROGRAM}

\subsection{Enerji Analizi}

Birinci kanun hesaplamalarının basitleştirilmesi için aşağıdaki kabuller yapılmıştır:

- Motor kararlı durumda çalışmaktadır.

- Yanma havası ve egzoz gazının her biri ideal gaz karışımıdır.

- Analizlerde kullanılacak yakıt dizel ve biyodizeldir.

- Yanma sabit basınçta gerçekleşmektedir.

- Yanma ürünleri kimyasal dengededir.

- Yanma havasının, yakıt ve egzoz gazının potansiyel ve kinetik enerjileri ihmal edilecektir.

Motora yakıt sayesinde giren enerji Eşitlik (1) kullanılarak hesaplanabilir. Bu denklemde $Q_{\text {giren }}$, yakıt enerjisini, $\mathrm{LHV}_{\mathrm{y}}$, yakıtın alt 1 sıl değerini, $\dot{\mathrm{m}}_{\mathrm{y}}$ ise yakıtın kütlesel debisini tanımlamaktadır.

$$
\mathrm{Q}_{\text {giren }}=\mathrm{LHV}_{\mathrm{y}} \times \dot{\mathbf{m}}_{\mathrm{y}}
$$

Motor gücünün hesaplanması için Eşitlik (2) kullan1lır. Denklemde $P_{e}$, motor gücünü $(k W), M_{e}$, motor torkunu $(\mathrm{Nm}), \mathrm{n}_{\mathrm{e}}$, motor devrini $(\mathrm{d} / \mathrm{d})$ göstermektedir.

$P_{e}=\frac{M_{e} \times n_{e}}{9549}$

İçten yanmalı bir motorun birinci kanun verimi ya da bir başka değişle 1sıl verimi $\left(\eta_{\text {เsıl }}\right)$ Eşitlik (3) ile hesaplanır.

$$
\eta_{1511}=\frac{P_{\mathrm{e}}}{Q_{\text {giren }}}
$$

İçten yanmalı motorlarda yakıtın yanması sonucu oluşan enerjinin bir kısmı kayıplar nedeniyle kullanılamamaktadır. $\mathrm{Bu}$ enerji kayıpları $\left(Q_{k a y ı p}\right)$ termodinamiğin birinci kanunundan yararlanılarak Eşitlik (4) yardımıyla hesaplanır.

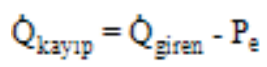

\subsection{Ekserji Analizi}

Ekserji, sistemin çevre ile mekanik, 1sıl ve kimyasal olarak dengeye ulaşana dek her motor çevriminde elde edilebilen yararlı iş olarak tanımlanabilir. İçten yanmalı motorlarda yakıt tarafından sağlanan ekserji, efektif güç ekserjisi (faydalı iş), egzoz ekserjisi, 1sı transferi ile meydana gelen ekserji ve yanma sonucu yıkılan ekserji olarak farklı türlere ayrı$\operatorname{lir}[17]$. 
Yanma havasının ve yakıtın silindirlere referans halde girdiği kabul edildiğinden, yanma havasının hem kimyasal hem de termomekanik ekserjisi, yakıtın ise termomekanik ekserjisi ihmal edilmiştir. Yakıtın kimyasal ekserjisi ( $\mathrm{e}_{\mathrm{F}}^{\mathrm{k} i m}$ ) hesaplanmak istenildiğinde Eşitlik (5) kullanılabilir [18]. Denklemdeki h, c, o ve s sırasıyla hidrojenin, karbonun, oksijenin ve kükürtün kütle kesirleridir. Yakıtın kimyasal ekserjisi, Eşitlik (6)'da verildiği üzere yakıt kütlesel debisi ( $\left.\dot{\mathrm{m}}_{\text {yal.t.t }}\right)$ ile çarpılarak bulunur.

$$
\begin{aligned}
& e^{\frac{k}{F}} \text { in }=\left[1.0401+0.1725 \frac{h}{c}+0.0432 \frac{0}{c}+0.2169 \frac{s}{c}\left(1-2.0628 \frac{h}{c}\right)\right] \times \operatorname{LHV}_{y} \\
& E_{\text {xyalut }}=e_{F}^{\frac{k}{i m}} \times \dot{m}_{y a k n t}
\end{aligned}
$$

Efektif güç ekserjisi $\left(E_{\mathrm{xg}}\right)$, aynı zamanda faydalı işe eşittir. Motorun efektif gücü de faydalı işe eşittir. Bu durumda Eşitlik (7) aşă̆ıdaki gibi yazılabilir.

$E_{x g}=P_{e}$

$\mathrm{Bu}$ çalışmada ekserji hesaplamaları, 1 atm $\left(\mathrm{P}_{\mathrm{o}}\right)$ basınç altında ve 298,15 K ( $\mathrm{T}_{\mathrm{o}}$ ) sıcaklıkta bulunan referans çevreyle bağıntılı olarak yapılmıştır. Bu referans çevrenin molar olarak \%75,67'si $\mathrm{N}_{2}, \%, 20,35$ 'i $\mathrm{O}_{2}, \% 0,03$ 'ü $\mathrm{CO}_{2}, \%, 3,12$ 'si $\mathrm{H}_{2} \mathrm{O}$ ve $\% 0,83$ 'ü diğer gazlardan oluşan ideal bir gaz kar1şımı kabul edilmiştir. Egzoz gazı ideal gazların bir karışımı olarak kabul edilebilir. Egzoz ekserjisi $E_{x e}$, Eşitlik (8) görülen egzoz gazlarının termomekanik ekserjileri $\left(e^{\text {ter }}\right)$ ile kimyasal ekserjilerinin $\left(e^{\text {kim }}\right)$ toplamlarıly egzoz kütlesinin çarpımına eşittir.

$$
\mathrm{E}_{\mathrm{xe}}=\dot{\mathrm{m}}_{\mathrm{e}} \times\left(\mathrm{e}^{\mathrm{ter}}+\mathrm{e}^{\mathrm{kim}}\right)
$$

Egzoz gazının termomekanik ekserjisi, $\bar{h}_{i}$ 'nin egzoz gazındaki i bileşenin özgül entalpisini, $\bar{s}_{i}$ 'nin egzoz gazındaki i bileşenin özgül entropisini, $\bar{h}_{0 i}$ 'nin ve $\bar{s}_{0 i}$ 'nin egzoz gazındaki i bileşenin referans haldeki özgül entalpisini ve özgül entropisini, $T_{0}$ 'ın referans sıcaklığını, $a_{i}$ 'nin i bileşeninin molar miktarını temsil ettiği Eşitlik (9) ile bulunabilir.

$$
e^{\text {ter }}=\sum_{i=1}^{n} a_{i} \times\left\{\left(\bar{h}_{i}-\bar{h}_{0 i}\right)-T_{0} \times\left(\bar{s}_{i}-\bar{s}_{0 i}\right)\right\}
$$

Egzoz gazının kimyasal ekserjisi, $y_{i}^{\varepsilon}$ 'nin referans çevredeki i bilişenin molar oranı, $y_{i}$ 'nin egzoz gazındaki i bileşenin molar oranı ve $\bar{R}$, nin evrensel gaz sabiti olduğu aşağıdaki gösterilen Eşitlik (10) ile bulunabilir.

$e^{k i m}=\bar{R} \times T_{0} \sum_{i=1}^{n} a_{i} \times \ln \frac{y_{i}}{y_{i}^{e}}$

Isı transferi ile meydana gelen ekserji kaybı, $T_{\text {soğ }}$ 'un soğutma suyu sıcaklığı olduğu Eşitlik (11) ile bulunabilir.

$$
E_{\text {xit }}=Q_{\text {kaypp }} \times\left(1-\frac{T_{0}}{T_{30 \check{g}}}\right)
$$

Yanma sonucu yıkılan ekserji $\left(E_{x y ı k}\right)$, Eşitlik (12) yardımı ile bulunur.

$$
E_{x y l k}=E_{x f}+E_{x y t}+E_{x g}+E_{x e}
$$

Motorda üretilen toplam entropinin bulunması için Eşitlik (13) kullanılabilir.

$\tau_{\mathrm{s}}=\frac{E_{x y l k}}{T_{0}}$

Motorun ekserjik verimi aşağıda verilen Eşitlik (14) ile bulunur.

$\eta_{\text {eks }}=\frac{E_{\mathrm{xg}}}{E_{\mathrm{xyakit}}}$

\subsection{Programın Yapisi}

Yakıt olarak dizel ya da biyodizel kullanan içten yanmalı motorların enerji ve ekserji analizlerinin daha hızlı ve güvenilir olarak yapılması için hazırlanan program, Visual Basic 6.0 kullanılarak yazılmıştır. Program beş aşamadan oluşmaktadır. Kolay kullanılabilen arayüz sayesinde programın ihtiyacı olan verileri programa girilebilmekte ve son aşamada analiz sonuçları görülebilmektedir.

Programın birinci aşaması olan enerji analizi Şekil 1.'de görülebilir. Bu aşamada kullanıcı motor torku, motor devri, yakıt debisi ve yakıtın alt 1 sıl değeri bilgilerini girmelidir. Eğer kullanıcı bu verileriden bir ya da birden fazlasını eksik bırakırsa, hesapla ve sayfayı değiştir butonları aktif olmayacaktır. Butonların aktif hale gelmesi için tüm verilerin eksiksiz girilmesi gereklidir. Ayrıca yapılan hesaplamalar sonucunda toplam 1sı kaybının eksi değerde çıkması halinde ekranda kullanıcıyı uyaran bir mesaj görülecektir. 


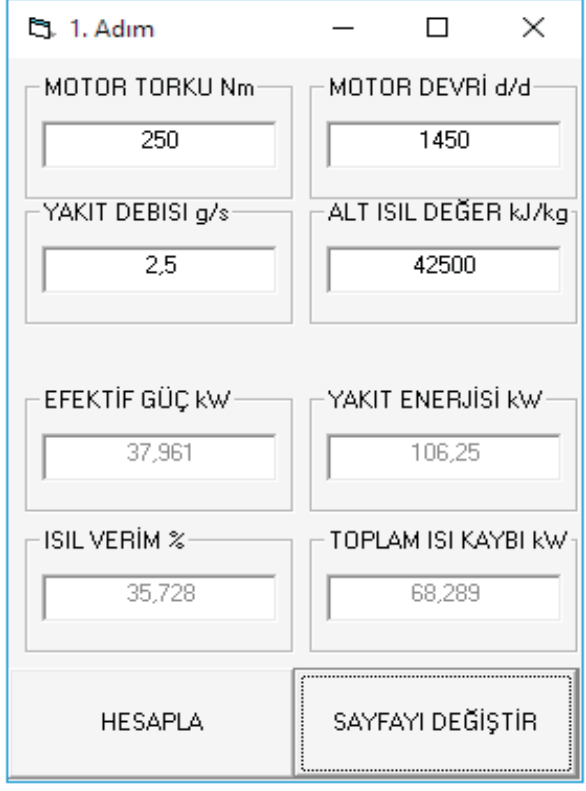

Şekil 1. Enerji analizi

Programın ikinci adımını yakıtın kimyasal ekserjisinin bulunması oluşturmaktadır. Şekil 2'de görülen bu adımda yakıtın içeriğinde bulunan moleküllerin kütlesel olarak birbirlerine olan oranları girilmelidir.

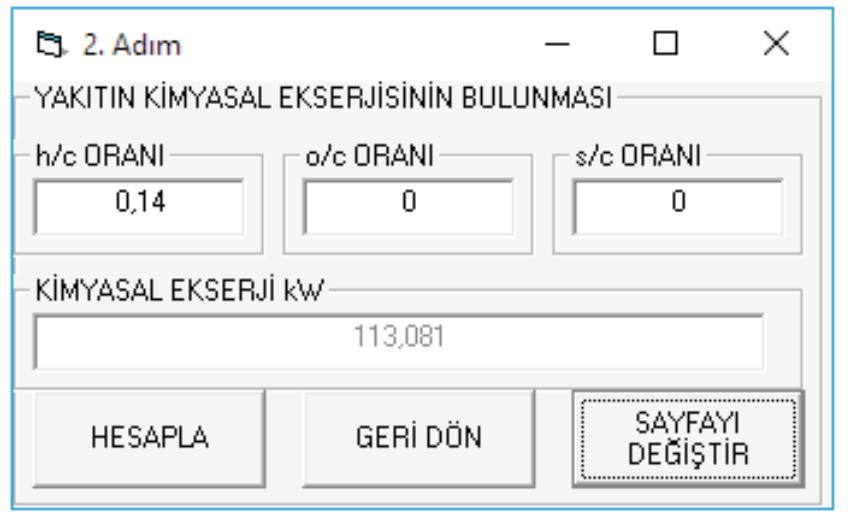

Şekil 2. Yakıtın kimyasal ekserjisinin bulunması

Eğer kullanıcı herhangi bir değeri eksik girerse program uyarı mesajı verecek ve sayfayı değiştir butonu pasif hale gelecektir. Sayfayı değiştir butonunun aktif hale gelebilmesi için tüm değerlerin girilmiş olması gereklidir. Yakıt oksijen ya da kükürt içermiyorsa o/c ve s/c oranları için sıfır (0) yazllmalıdır.

Egzoz gazı içerisindeki yanma ürünlerinin gerçek kütlelerinin bulunması egzoz ekserjisinin hesaplanması için gerekli bir işlemdir. Şekil 3’te görüleceği üzere öncelikle yakıtın yanması sonucunda ortaya çıkan emisyonlar belirlenir. Bu çalışmada egzoz gazının oksijen, karbondioksit, karbonmonoksit ve azottan oluştuğu kabul edilmiştir. Hidrokarbon, azot oksit ve azot dioksit gazlarının emisyonları çok düşük olduğundan gerçek yanma denkleminde yer almamışlardır. Denklem oluşturulurken egzoz emisyon cihazından ölçülen değerler kulanılmıştır.

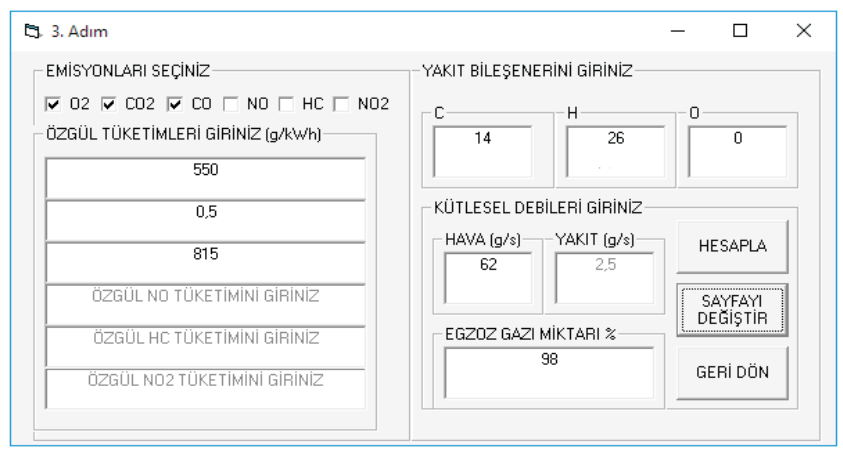

Şekil 3. Egzoz gazı içerisindeki ürünlerin gerçek kütlelerinin bulunmas1

Bununla birlikte program, kullanıcının isteğine bağlı olarak hidrokarbon, azot oksit ve azot dioksit gazlarının analize dahil edilmesine olanak sağlamaktadır. Yanma odasından çıkan egzoz gazının kaybı sisteme girilerek emme havası ve yakıt debilerine bağlı egzoz debisi hesaplanır.

Şekil 4'te egzoz gazlarının entalpi ve entropi değerleri görülmektedir. Dört numaralı adımda değerlerin hesaplanabilmesi için referans çevre sıcaklı̆̆ının programa girilmesi gereklidir. Referans sicaklık değeri $25^{\circ} \mathrm{C}$ olarak belirlenmiştir. Bununla birlikte kullanıcı isterse farklı bir referans sıcaklık değeri girebilir.

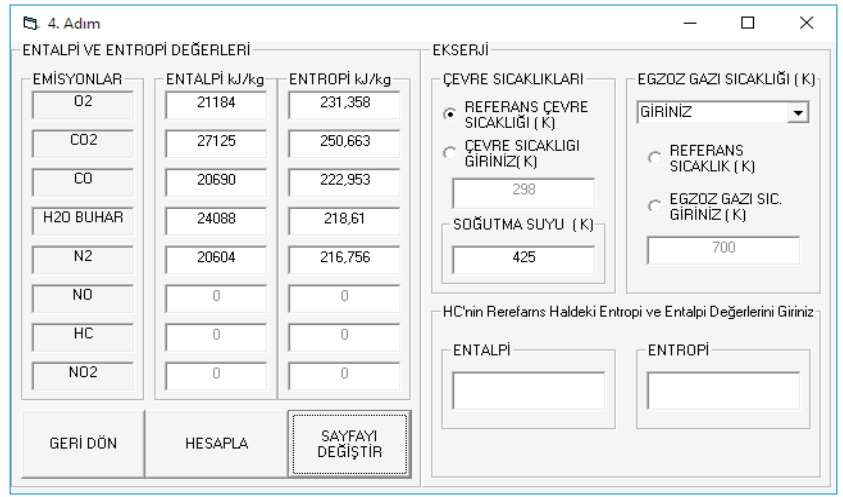

Şekil 4. Egzoz entalpi ve entropi değerlerinin hesaplanması 
Üç numaralı adımda seçilen egzoz gazı bileşenlerinin entalpileri ve entropileri hesaplanırken seçilmeyen bileşenlerin entalpileri ve entropileri hesaplanmayarak pasif durumda kalacaktır. Entalpilerin ve entropilerin bulunmasında Janaf tabloları [19] kullanılmıştır. Hidrokarbonun entalpi ve entropisi Janaf tablolarınında bulunmadığından hesaplama yapmak istenildiğinde bu değerler literatürden alınabilir. Ayrıca dördüncü adımda motorun soğutma suyu girilerek 1s1 transferi ile meydana gelen ekserji kaybı hesaplanabilir.

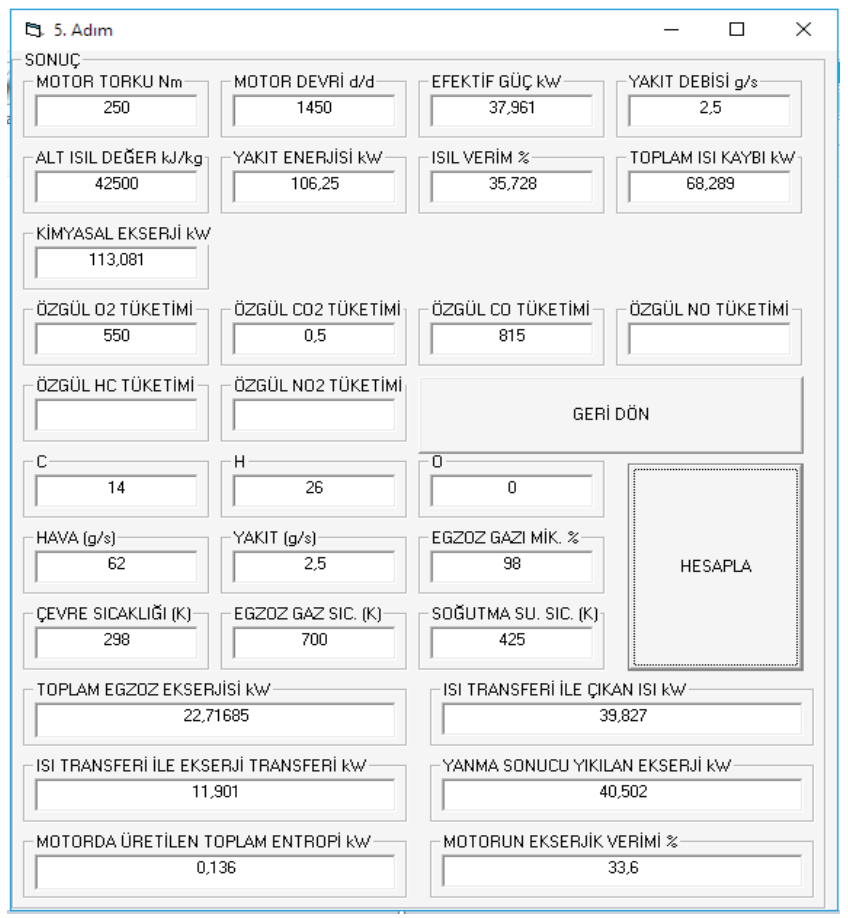

Şekil 5. Değerler ve hesaplamalar

Şekil 5.'te programın son aşaması görülmektedir. Bu aşamada programa diğer aşamalarda girilen veriler ve analiz sonuçları incelenebilir.

\section{SONUC}

Enerji ve ekserji analizlerinde, çok sayıda bileşene ihtiyaç duyulmakta ve bu bileşenlerin dahil olduğu matematiksel hesaplamalar yapılmaktadır. Bu çalışmada dizel veya biyodizel yakıtlı bir içten yanmalı motor için Visual Basic Programı kullanılarak enerji ve ekserji analizi yapabilen bir programın yapısı ve uygulaması gösterilmiştir. Programın kolay kullanımı ve etkileşimli ara yüzü sayesinde, kullanıcıların matematiksel işlemlerde hata yapma olasılıkları en aza indirilirken, hızlı ve güvenilir sonuçlar elde edilebilecektir.

\section{KAYNAKLAR}

[1] Ozkan, M. (2015). A Comparative Study on Energy and Exergy Analyses of a CI Engine Performed with Different Multiple Injection Strategies at Part Load: Effect of Injection Pressure. Entropy, 17(1): p. 244-263.

[2] Tsatsaronis, G. (1993). Thermoeconomic Analysis and Optimization of Energy-Systems. Progress in Energy and Combustion Science, 19(3): p. 227-257.

[3] Gharehghani, A., Hosseini, R., Mirsalima, M. \& Yusaf T. F. (2015). A comparative study on the first and second law analysis and performance characteristics of a spark ignition engine using either natural gas or gasoline. Fuel, 158: p. 488493.

[4] Jena, J. \& Misra, R., D. (2014). Effect of fuel oxygen on the energetic and exergetic efficiency of a compression ignition engine fuelled separately with palm and karanja biodiesels. Energy, 68: p. 411-419.

[5] Nieminen, J. ve Dincer, I. (2010). Comparative exergy analyses of gasoline and hydrogen fuelled ICEs. International Journal of Hydrogen Energy, 35(10): p. 5124-5132.

[6] López, I., Quintana, C. E., Ruiz, J.J., Cruz-Peragón, F. \& Dorado, M.P. (2014). Effect of the use of olive-pomace oil biodiesel/diesel fuel blends in a compression ignition engine: Preliminary exergy analysis. Energy Conversion and Management, 85: p. 227-233.

[7] Gökalp, B., Soyhan, H. S., Saraç, H. İ., Bostan D. \& Şengün. Y. (2009). Biodiesel Addition to Standard Diesel Fuels and Marine Fuels Used in a Diesel Engine: Effects on Emission Characteristics and First - and Second-Law Efficiencies. Energy \& Fuels,. 23: p. 1849-1857.

[8] Magno, A., Mancaruso, E. \& Vaglieco, B. M. (2015). Effects of a biodiesel blend on energy distribution and exhaust emissions of a small CI engine. Energy Conversion and Management, 96: p. 72-80.

[9] da Costa, Y. J. R., de Lima, A. G. B., Filho, C. R. B. \& Lima, L.A. (2012). Renewable \& Sustainable Energy Reviews, 16(7): p. 4651-4660.

[10] Kul, B. S. \& Kahraman, A. (2016). Energy and Exergy Analyses of a Diesel Engine Fuelled with Biodiesel-Diesel Blends Containing 5\% Bioethanol. Entropy, 18(11).

[11] Ghahfarokhi, R. F., Khalilarya, S. \& Ebrahimi, R. (2013). Energy and Exergy Analyses of Homogeneous Charge Compression Ignition Engine. Thermal Science, 17(1): p. 107117.

[12] Jafarmadar, S. \& Mansoury, M. (2015). Exergy analysis of air injection at various loads in a natural aspirated direct injection diesel engine using multidimensional model. Fuel, 154: p. 123-131.

[13] Jafarmadar, S. \& Nemati, P. (2016). Exergy analysis of diesel/biodiesel combustion in a homogenous charge compression ignition (HCCI) engine using three-dimensional model. Renewable Energy, 99: p. 514-523. 
[14] Gümüş, M. \& Atmaca, M. (2013). Energy and exergy analyses applied to a CI engine fueled with diesel and natural gas. Energy Sources Part a-Recovery Utilization and Environmental Effects, 35(11): p. 1017-1027.

[15] Sayın, C., Hosöz, M., Çanakçı, M. \& Kilicaslan, I. (2007). Energy and exergy analyses of a gasoline engine. International Journal of Energy Research, 31(3): p. 259-273.

[16] Khaliq, A. (2015). Energy and exergy analyses of a hydrogen fuelled HCCI combustion engine combined with organic Rankine cycle. International Journal of Exergy, 17(2): p. 240-265.
[17] Javaheri, A., Esfahanian, V., Salavati-Zadeh, A. \& Darzi, M. (2014). Energetic and exergetic analyses of a variable compression ratio spark ignition gas engine. Energy Conversion and Management, 88: p. 739-748.

[18] Kotas, T.J. (1986). Exergy Method of Thermal and Chemical-Plant Analysis. Chemical Engineering Research \& Design, 64(3): p. 212-229.

[19] Çengel, Y. \& M. A. Boles. (2012). Mühendislik Yaklaşımıyla Temodinamik. İstanbul: Güven Bilimsel. 946. 